\title{
GIANT INTRATHORACIC PLEURAL LIPOMA- A CASE REPORT
}

\author{
Hridoyjit Kakoti', Pronami Borah², Rajat Mala3, Rudra Kanta Gogoi', Cheng Khow Weingken ${ }^{5}$
}

1Postgraduate Trainee, Department of Radiodiagnosis, Assam Medical College and Hospital, Dibrugarh, Assam. ${ }^{2}$ Associate Professor, Department of Radiodiagnosis, Assam Medical College and Hospital, Dibrugarh, Assam. 3 Postgraduate Trainee, Department of Radiodiagnosis, Assam Medical College and Hospital, Dibrugarh, Assam. 4 Professor, Department of Radiodiagnosis, Assam Medical College and Hospital, Dibrugarh, Assam.

5 Postgraduate Trainee, Department of Pathology, Assam Medical College and Hospital, Dibrugarh, Assam.

HOW TO CITE THIS ARTICLE: Kakoti H, Borah P, Mala R, et al. Giant intrathoracic pleural lipoma- a case report. J. Evolution Med. Dent. Sci. 2017;6(94):6916-6917, DOI: 10.14260/jemds/2017/1499

\section{PRESENTATION OF CASE}

A 3 years old male patient came to the Department of Radiodiagnosis, Assam Medical College, Dibrugarh, Assam with complaints of swelling over the right anterolateral chest wall associated with difficulty in breathing since 20 days.

On examination there is a soft, non-tender swelling in the anterolateral aspect of right chest wall (Figure 1). The patient was found to have absent breath sounds and dullness on percussion in the right lower lung field. Laboratory findings were normal. The patient was subjected to a chest x-ray, which showed a large homogenous opacity in the right hemithorax obscuring the right hemidiaphragm, right cardiophrenic angle and right heart border and displacing the mediastinum to the contralateral side (Figure 2). Patient then underwent CT scan examination of the thorax that revealed a huge fat density ( -65 to -105 Hounsfield units) lobulated lesion with scattered areas of soft tissue density and septations in right hemithorax causing passive collapse of the underlying right middle and lower lobe with contralateral mediastinal shift. The lesion was protruding anterolaterally into the extrapleural space through the 6th and $7^{\text {th }}$ right intercostal spaces (Figure 3). A provisional diagnosis of intrathoracic pleural lipoma was made.

\section{DIFFERENTIAL DIAGNOSIS}

Pleural lipoma, pleural liposarcoma.

\section{PATHOLOGICAL DISCUSSION}

The patient underwent right thoracotomy which revealed a lobulated, yellowish soft tumour which had a smooth surface. There was no adhesion between the tumour and the surrounding organs, and the entire mass was successfully resected. Histopathologic examination revealed an encapsulated tumour with abundant mature adipocytes without evidence of sarcomatous changes consistent with pleural lipoma (Figure 4).

Lipomas are benign mesenchymal neoplasm, commonly seen in adults. They account for approximately half of all soft tissue tumours and $80 \%$ of all benign fat-containing neoplasms. Conventional lipomas can arise in subcutaneous

'Financial or Other Competing Interest': None.

Submission 18-08-2017, Peer Review 01-12-2017,

Acceptance 07-12-2017, Published 18-12-2017.

Corresponding Author:

Dr. Hridoyjit Kakoti,

Postgraduate Trainee,

Department of Radiodiagnosis,

Assam Medical College and Hospital,

Dibrugarh, Assam.

E-mail: hridoyjitkakoti@gmail.com

DOI: $10.14260 /$ jemds/2017/1499 tissue (superficial lipoma), in deep soft tissue (deep lipoma) or on surface of bone (parosteal lipoma). However, intrathoracic lipomas are rare and can arise from the mediastinum, diaphragm, bronchus, lung or thoracic wall.[1,2]

Thoracic or pleural lipomas originate from submesothelial layers of parietal pleura and can extend into the subpleural, pleural or extrapleural space, and they exhibit slow growth. They can arise from the lateral wall as well from the mediastinal or diaphragmatic pleura. ${ }^{[3]}$

Lipomas can also be divided into two classes: (1) Hourglass or dumbbell lipomas that pass through intercostal space or the thoracic inlet as seen in our case; and (2) Purely intrathoracic lipomas. ${ }^{[4]}$

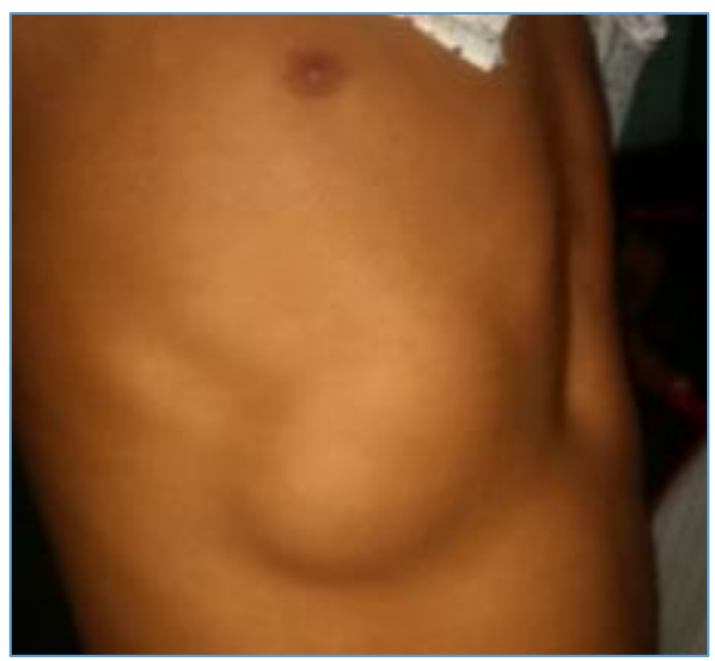

Figure 1. Swelling over Anterolateral aspect of Right Chest Wall

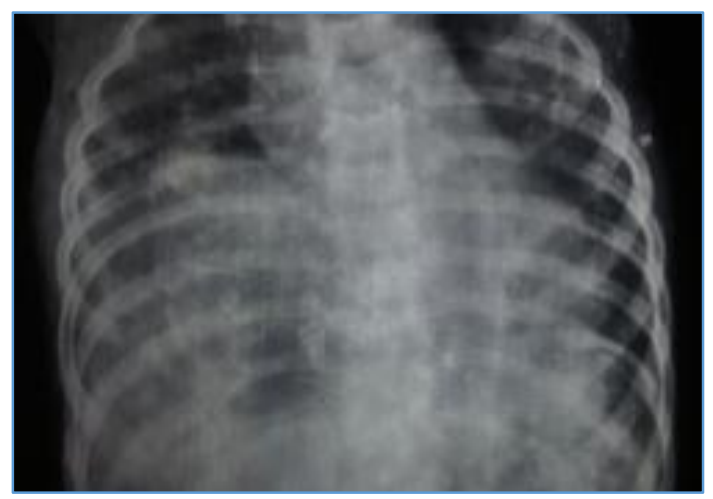

Figure 2. Chest X-ray (PA view) showing a Huge Homogenous low dense Opacity in the Right Thoracic Cavity obscuring the Right Cardiophrenic Angle, Right Hemidiaphragm and Right Heart Border with Mediastinal Shift 


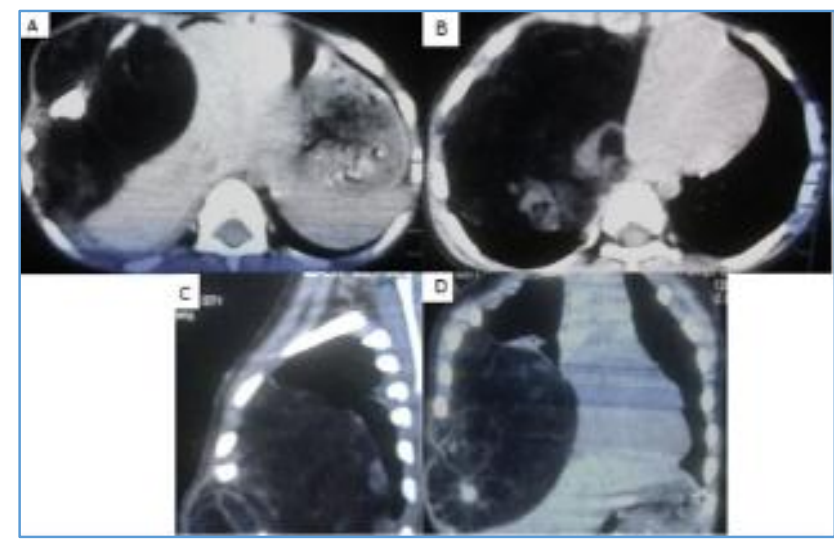

Figure 3. (A, B Axial; C Sagittal; D Coronal Images) showing a Fat Density Lobulated Lesion with Areas of Soft Tissue Density and Septations in Right Hemithorax along with its Extension and Contralateral Mediastinal Shift

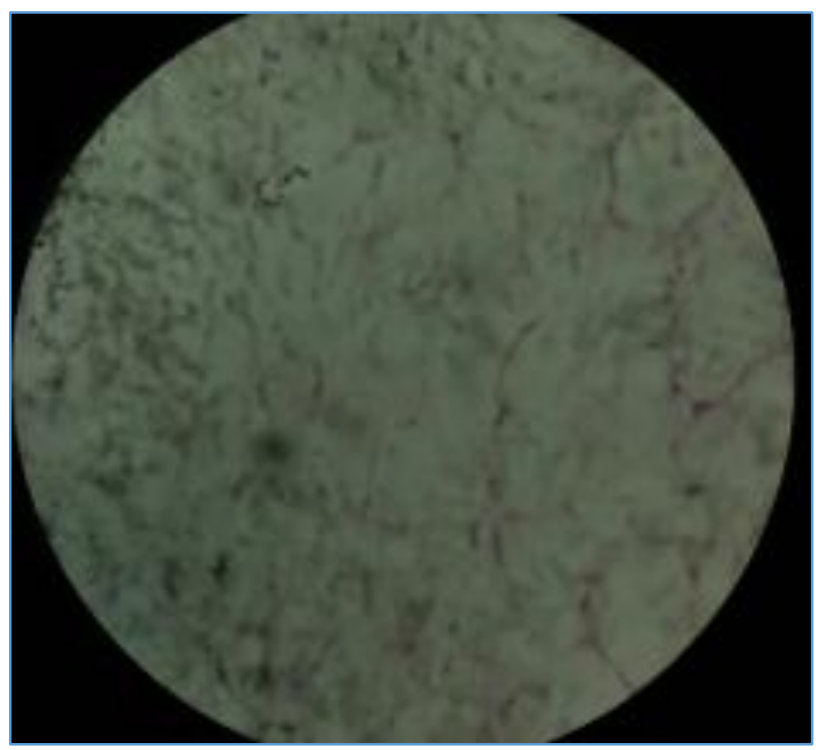

Figure 4. HPE Image showing Abundant Adipocytes

\section{DISCUSSION OF MANAGEMENT}

Most patients remain asymptomatic, but since lipomas are able to grow to a large size they may provoke compression symptoms. Symptoms such as dyspnoea and dysphagia due to local compression on adjacent structures, such as the trachea or oesophagus.[4] CT allows a definitive diagnosis when it demonstrates a homogeneous fat attenuating mass ( -50 to 150 Hounsfield units or HU) forming obtuse angles with the chest wall and displaces adjacent pulmonary parenchyma and vessels. The density may not be entirely uniform, because lipomas often contain fibrous stroma.[5]

The management strategy for pleural lipomas is still controversial. An observation principle with clinical and radiological follow-up may be suitable for elderly patients and those in poor general condition, especially in the presence of small and asymptomatic lesion.[4] However, surgical treatment is generally definitive and the incidence of recurrence is extremely low and essentially related to incomplete removal of the lesion. [5]

CT scan plays a pivotal role in clarifying and characterising nonspecific findings of chest x-rays and helps in differentiating pleural from extrapleural lesions. Moreover, CT helps in knowing the nature and extension of the lesion and helps in its precise characterisation and diagnosis. Although, pleural lipoma is a rare benign neoplasm, but when large it can cause severe compression symptoms and give rise to complications. Moreover, the lesion cannot always be differentiated from liposarcoma with imaging methods and definitive diagnosis requires pathologic correlation.

\section{REFERENCES}

[1] Zidane A, Atoini F, Arsalane A, et al. Parietal pleura lipoma: a rare intrathoracic tumor. Gen Thorac Cardiovasc Surg 2011;59(5):363-6.

[2] Politis J, Funahashi A, Gehlsen JA, et al. Intrathoracic lipomas. Report of three cases and review of the literature with emphasis on endobronchial lipoma. J Thorac Cardiovasc Surg 1979;77(4):550-6.

[3] Cabral P, Baptista M. Thoracic lipomas simulating metastasis. J Bras Pneumol 2013;39(5):630-2.

[4] Chen M, Yang J, Zhu L, et al. Intrathoracic giant pleural lipoma: case report and review of the literature. J Cardiothorac Surg 2013;8:196.

[5] Alfano DD. Case report of pleural lipoma: "wait and see" or surgery? International Journal of Medicine and Pharmacy 2014;2(2). 